\title{
The New Safety Trends: The Challenges through Industry 4.0
}

\author{
DI NARDO MARIO ${ }^{1}$, BOROWSKI PIOTR $^{2}$, MARYAM GALLAB $^{3}$, MURINO TERESA $^{4}$, \\ YU HAOXUAN ${ }^{5}$ \\ ${ }^{1}$ Department of Materials Engineering and Operations Management, \\ University of Naples "Federico II", Naples, ITALY \\ mario.dinardo@unina.it \\ ${ }^{2}$ Institute of Mechanical Engineering, Warsaw University of Life Sciences, Warsaw, POLAND \\ ${ }^{3}$ Mines-Rabat School, MOROCCO \\ gallab@enim.ac.ma \\ ${ }^{4}$ Department of Materials Engineering and Operations Management, \\ University of Naples "Federico II", Naples, ITALY \\ murino@unina.it \\ ${ }^{5}$ School of Resources and Safety Engineering, Central South University, Changsha, CHINA \\ yuhaoxuan@csu.edu.cn
}

\begin{abstract}
Industrial engineering achieved rapid growth in providing safety measurements in all industries, following different safety policies to prevent faults in sectors. Industrial safety is an essential feature to give an accident-free environment. Implementation of safety policies and measurements encourage industrial people to work in various perilous conditions. Industries prepare their safety policy and safety manual to identify various faults and risks. It is necessary to create awareness to industry workers, and industries maintain special departments for safety. Safety guidelines prevent occupational injuries and accidents. Safety rules and regulations reduce the waste of human and other resources in industries. The study evaluates safety models used in industry to identify issues involved in the selection, implementation, and evaluation. This research provides insight into the overall process for industrial safety and, most essential, overviews on the methodology. Predicting industrial faults and risks emphasized the industrial engineering process and used machine learning algorithms for classifications. Many issues and challenges discussed industrial safety and provided novel innovation ideas for researchers.
\end{abstract}

Key-Words: - Safety Culture, Safety 4.0, Industry 4.0, Risk Management

Received: June 19, 2021. Revised: December 14, 2021. Accepted: December 29, 2021. Published: January $17,2022$.

\section{Introduction}

Industrial safety necessitates a consistent way of life and a positive mindset. Safety refers to the absence of danger or injury. Additionally, the phrase "safety" refers to the steps taken by individuals to avoid accidents, harm, and risk. Additionally, advances in workplace safety have been made to benefit employee health. Management is accountable for employee safety while on the job.

Therefore, research and discussion of industrial safety are becoming increasingly important and the focus of all societies in the world. For example, according to the MENA Report (2021), the popularization and use of safety helmets have gradually become the focus of development in central Africa, the Middle East, and other backward industrial regions. For example, H. Ebrahimi and S. M. Kharghani Moghadam (2021) recently proposed an information management system for industrial cities, which is used to strengthen the construction of industrial security in cities. Also, Nakhal A, A. J. et al. (2021) came up with the concept of an intelligent industrial information system to ensure the efficiency and safety of industrial production.

All undesirable events in the workplace that can result in death, ill health, injury, damage, or other loss must be thoroughly evaluated; personnel must be trained to protect against and eradicate them. Similarly, any critical hazards, i.e., the source/situation that poses a risk of injury or illness, must be identified and action plans developed to mitigate them.

For example, A. A. Artamonov et al. (2021) used mathematical models to assess the impact of chemical production on industrial safety; G. Vasilescu et al. (2021) did the same, and they used computer modeling for integration to assess the risks associated with different industrial hazard scenarios (shock wave propagation, debris propagation) and the impact on location; S. Meramo-Hurtado et al. 
(2021) developed an inherent safety analysis of chitosan microbeads modified with $\mathrm{TiO} 2$ nanoparticles for mass production using the inherent safety index (ISI) method; Li, S. et al. (2021) assessed the impact of some mining industry activities on environmental safety.

It is not only sufficient to care for safety but other two inter-related aspects, viz., health (wellbeing of employees) and environment, are also given equal importance and considerations. For example, Yu, H. et al. (2021) thought about using "safe" new industrial products to benefit mankind, and he developed an intelligent scraper; Li, $\mathrm{S}$ et al. (2021) and Yu, H et al. (2021) used communicationbased train control system (CBTC system) to improve the industrial transport efficiency to benefit mankind. All these three elements, i.e., health, safety, and environment (also known as HSE), are interrelated and affect each other. For instance, if employee health is not given due regard, it may lead to accidents (Henmi et al., 2016).

If the industry pollutes the environment around its facilities, it will hurt employees' health, eventually harming productivity. Safety can be guaranteed only when health and the environment are under control. As a result, each industry bears specific environmental stewardship and public health responsibilities: Guo, Q. et al. (2021) and Nardo M.D, et al (2021) have considered the impact of industrial pollution on the environment and try to solve the problem.

We examined several industrial safety techniques that have aided in improving industrial engineering plant safety in this article. The remainder of the study is divided into many sections that discuss various industrial safety mechanisms and their significance for industrial safety procedures. It concludes with a discussion of the findings and potential directions for research.

\section{Literature Review}

\subsection{Industrial Safety Models}

This section discussed the literature review on different safety approaches to improve industrial safety in engineering plants.

RHR is an approach suggested by Yoon et al. (2008) for discovering high- $\mathrm{R}$ connections that is entirely automated. The use of high resistance connections in industrial facilities' electrical distribution systems causes overheating, reduces efficiency, and threatens safety. The RHR approach regulates the circumstances upstream and downstream of the industrial facility, increasing the dependability of the electrical distribution system and the facility's overall safety.

However, the system fails in the maintenance of monitor alarms.

Henmi et al. (2016) proposed a machine learning approach to the early detection of plant faults. The abnormal plant state signal is not available before failures occur. The previous mechanisms can measure the normal state of the plants only. This research work introduced a machine learning approach called Support Vector Machine (SVM) to overcome this problem. This approach better classifies the state of the plant, which is normal or abnormal. For advanced classification, the Kernel Gaussian technology was also used. Nevertheless, this algorithm is flexible for only water plants. There is no scope for other industrial plants.

De Souza (2014) used the Support Vector Machines (SVM) approach to identify and diagnose faults in his system. This paper discusses two approaches: support vector machines for classification (Support Vector Classification - SVC) and support vector machines for regression (Support Vector Regression - SVR). SVM approach shows promise for process monitoring in instances where an automatic monitoring system is required to improve process efficiency while also ensuring worker and public safety in the workplace. Using both approaches in a process monitoring system at the same time allows researchers to make use of the rapid detection time provided by the SVR approach and the classification capabilities provided by the SVC-based methodology. According to the comparison of the SVM techniques and the PCA methods, the SVM methodology, which requires less information than the PCA methodology, performs better than the conventional approach for fault identification in the non-isothermal reactor for the faulty situation under consideration.

Pfeffer et al. (2015) proposed the HAZOP approach for industrial safety. The modular process plants should be integrated with safety engineering. However, safety solutions and relevant measures are identified by the HAZOP efficiently. But the proposed approach does not give automatic solutions for plant safety. The present industry needs dynamic methods for plant maintenance and safety.

Choi et al. (2011) proposed an industrial pipe rack safety monitoring system based on Wireless Sensor Networks (WSN). The system is designed and implemented for large-scale networks. The system consists of many safety devices such as sensor nodes, gateways, and servers. Based on the safety sensors, it can be monitored and provide 
safety guidelines for industrial plant management. However, this research work concludes that the proposed system maximizes safety maintenance and minimizes risks. However, the system does not provide security maintenance. The WSN based system cannot complete reliable data transmission due to large-scale networks.

Laurenty et al. (2010) offer an approach for configuring instrumentation systems to meet the legal requirement of maintaining high reliability in regular and fail-safe operation circumstances. A series of models operating as Expert systems is proposed to attain the required state: each model is responsible for watching and diagnosing pipeline leaks in real-time. In addition, the suggested system validates the activities under the business rules that have been applied to it. It is necessary to apply several systems approaches to perform its purpose, including fuzzy logic, neural networks, genetic algorithms, and statistical analysis. This solution is one option to be used as an aid in various industry fault detection problems.

G. H. Choi and B. G. Loh (2017) focused on the dynamic characteristics of industrial safety systems in the Republic of Korea and their impact on safety performance. This dynamic property is essential for the reconstruction of industrial safety systems. They also studied the impact of damping and elastic properties of industrial safety system models on safety performance and explained the feedback control performance in terms of cost and benefit. They also explored the implications of restructuring industrial safety systems for safety policy. They argued that the strong correlation between safety budget and industrial accident rate makes it possible to model industrial safety systems with these variables as inputs and outputs, respectively, and that weaker elastic characteristics and stronger damping characteristics can achieve more effective and efficient industrial safety systems.

J. Le Coze (2013) described what is defined as the sensitization model. They proposed that the model was developed to support empirical and methodological research in different high-risk industries, to assist current and future industrial safety assessment practices by considering the input of the social sciences, in particular reflecting their insights into significant incidents. At the same time, they described the design principles of this exploration in order to generate a sensitive model for security assessment. The model was developed by combining two general management and sociological (safety) literature models. In this model, security was viewed as a dynamic interaction between multiple dimensions, including technological Design and tasks, organizational structural and functional characteristics, and cognitive, cultural, and power issues, at various levels of analysis.

From the perspective of system safety and control theory, W. Li, L. Zhang, and W. Liang (2017) put forward a model of accident cause analysis and classification, taking human, machine, management, environment, information and resources as system factors, and then put forward a new accident mechanism. At the same time, they analyzed and classified the causes of the Texas City refinery explosion according to their proposed safety incident analysis mechanism.

\subsection{New Arising Risks}

The increasing complexity of manufacturing facilities forces companies to move towards decentralized decision-making. At the moment, decentralized instances may make decisions using artificial intelligence incorporated into people or equipment. During the Industrial Revolution, the advent of Industry 4.0 impacted $\mathrm{OH} \& \mathrm{~S}$, particularly in terms of job diversity, management, and other organizational variables.

The risk assessment must continue to change to handle current and future concerns. While digitalization creates opportunity, it also adds complexity to cyber-physical systems. Zio Enrico (2018). Climate warming and major natural occurrences are putting our infrastructures in growing jeopardy. These sources of danger are unknown, making them challenging to explain and model statistically. Many emerging research and development directions are discussed, including the use of simulation to identify and explore accident scenarios, the extension of risk assessment into the context of resilience and business continuity, the reliance on data for dynamic and condition monitoring-based risk assessment, and the safety and security assessment of cyber-physical systems.

According to Brocal et al. (2019), risk governance, risk management, occupational health and safety management systems, and emerging risk management comprise the four fundamental risk management system categories in Industry 4.0. The next section discusses the many models listed, including historical and contemporary models.

\subsubsection{Risk Management Models}

From an international level, we propose a framework for risk governance. This framework provides tactics for designing and implementing comprehensive assessments and strategies to manage these issues. Risk governance includes the application of governance principles to risk identification, 
assessment, management, and communication. Therefore, the risk management process may be regarded as integrated with the risk governance process.

The International Standard for Managing Risk (ISO 31000:2018 provides guidelines and a common approach for all risk types. Risk management is defined as an organization's coordinated activities to direct and control risks across the organization. SRM (also known as risk management) involves prevention, mitigation, adaptation, and sharing, to reduce risk. Although the new industry was arising and reinforcing, no guide was provided by the new standardization.

A management system is a set of interrelated or interacting elements of an organization to establish policies and objectives, and processes to achieve those objectives.

L. M. Steege and B. Pinekenstein (2016) thought that to solve the professional nursing system fatigue and reduce the risks associated with the nurse's need of strategic management and the high-level decisionmaking and daily management through operational and tactical operations. Therefore, they applied risk management models in the professional nurse assessment of fatigue risks; the model nurse includes support for safety and welfare in the culture of monitoring and decision support tools.
M. Jafari et al. (2011) presented a multi-stage research approach to develop knowledge risk management models in project-based organizations in Iran. This analytical model can be used to prepare a broad assessment of the risk of knowledge loss in a project-based organization and to provide recommendations on preservation plans to mitigate its impact. D. Kern et al. (2012) developed an upstream supply chain risk management model that links risk identification, risk assessment and risk mitigation with risk performance and validated the model empirically. The model also includes the impact of the continuous improvement process on identification, assessment, and mitigation. M. M. Silverman (2014) even applied the risk management model to psychiatry.

\section{Industrial Safety Issues}

The safety problems in industrial engineering through the plants in endanger. The different emerging issues are impacting industrial safety. Such issues are tendering, customer system and practices, time pressure, managing safety, dangerous work tasks, communication, hazard identification. Figure 1 represents the manage safety problems in industrial engineering plants.

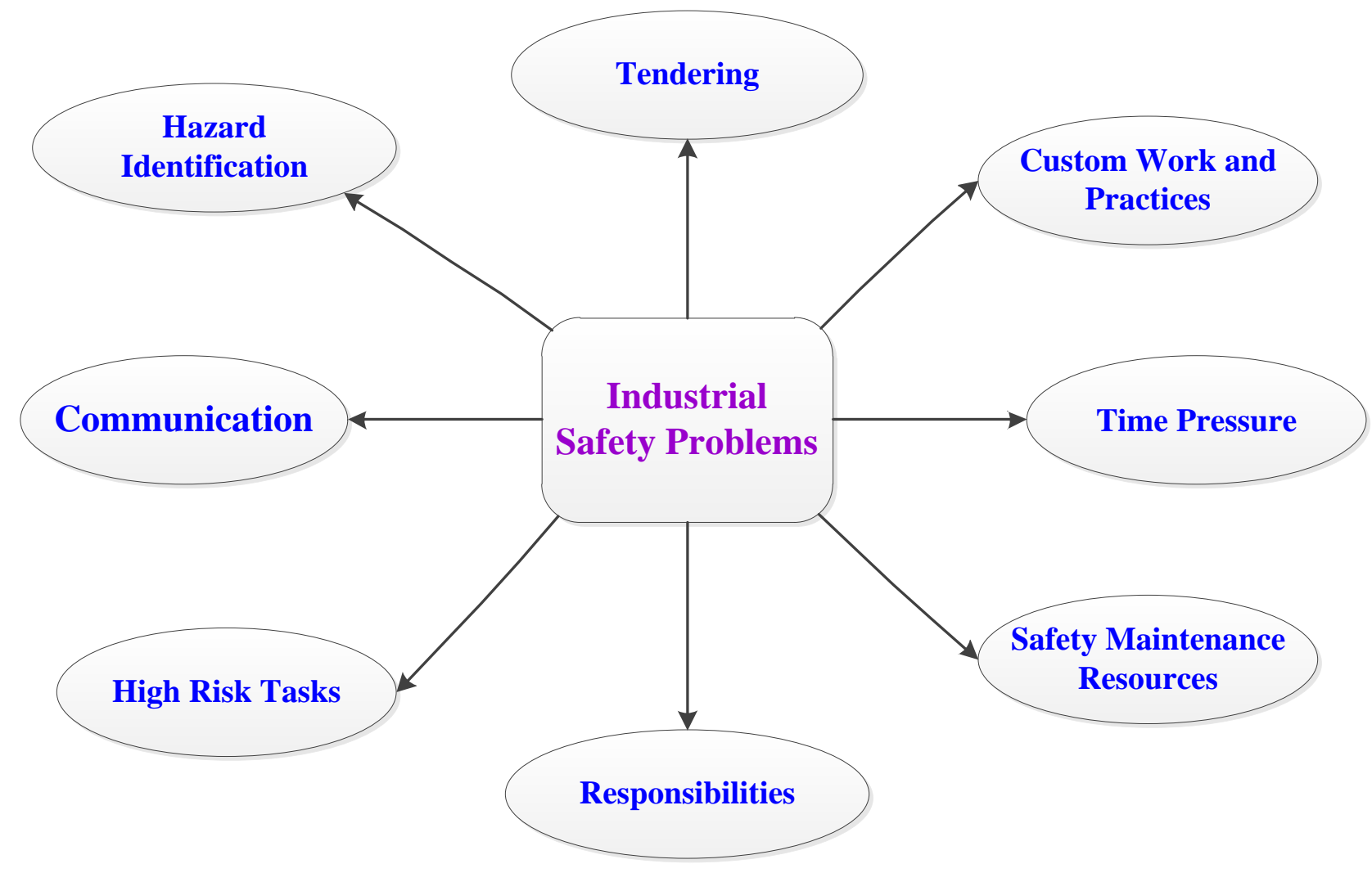

Fig. 1: They manage safety problems in industrial engineering plants. 


\subsection{Tendering}

The tendering system indirectly represents the importance of safety risks. The industrial people select only low price service providers. The competition between the service can divert them into low bids and less spent on industrial safety even though the budget problems reduce the safety performance and increase the accident rates. Neglecting the safety in tendering is the main disadvantage of industrial safety.

\subsection{Custom Work and Practices}

The customers worked in different companies and different work locations. Each industrial company has custom policies in the work environment. The unfamiliar work tasks and work locations and low awareness about the hazards may lead to high risk in industrial plants. The complexity of management safety is increased due to different management policies between the service providers and customers. To ensure safety, customers should know the work policies and fully gain awareness of risk hazards.

\subsection{Time Pressure}

The customers worked in different companies and different work locations. Each industrial company has custom policies in the work environment. The unfamiliar work tasks and work locations and low awareness about the hazards may lead to high risk in industrial plants. The complexity of management safety is increased due to different management policies between the service providers and customers. To ensure safety, customers should know the work policies and fully gain awareness of risk hazards.

\subsection{Safety Maintenance Resources}

The industries are suffering from maintenance safety resources and implementing safety policies. Smallscale industries have insufficient resources to provide safety in industrial plants. Especially these industries do not have time, money, and human resources to manage safety efficiently. In the case of large-scale industries failed in the implementation of safety maintenance. Industrial engineering safety has emerging problems due to inadequate resources that are emphasized.

\subsection{Responsibilities}

Mostly the management of safety is unaware of service providers. Many industries miss the decryption of safety responsibilities, and providers do not know their requirements. Both the companies and service providers often forget to ensure safety procedures. Due to the limited abilities, the service will not take responsibility for improving industrial engineering plants' safety.

\subsection{High-Risk Tasks}

Maintenance and installation work involved the most significant risks. Besides, an employee of industrial companies works under different conditions. The temporary employees are not aware of the worksite and the work's risk due to the high risk of tasks that the insufficient knowledge employees perform. The other problems also lead to high-risk accidents, such as soft budget works, tight schedules, fewer experience workers, unfamiliar workplaces.

\subsection{Communication}

The different work was that operating parties did not transfer the work importance and safety models between them. The lack of communication among the various work professionals leads to safety problems in industrial plants. How service is provided to the customer affects the quality of service. Poor communication between the provider and the client may, at worst, put the safety of both the provider and client's workers at risk. Most providers believe that customers are not as cavalier about their opinions as staff members. Furthermore, some managers consider that providing critical customer feedback and identifying unsafe practices are part of their responsibility.

\subsection{Hazard Identification}

Many industries do not have the facility to systematically identify hazards and cause poor safety procedures. Many industries are negligent in the implementation of the hazard identification system.

\section{Industrial Engineering Safety Challenges}

In industrial engineering manage safety is essential to improve industrial performance. Even the fourth generation industry has challenges in safety management, such as lack of supervision, poor safety policies, equipment quality, technology impact, weak precautions.

\subsection{Lack of Supervision}

Supervision is essential for safety management in industrial engineering. Safety management has terms and policies. Every department in industrial engineering has awareness about safety management policies. The safety management department observes the safety policies implementation in industries. The management department cannot 
implement safety management policies, which leads to a rise in safety problems. If the supervision department does not inspect the issues, it will affect safety management. Due to lack of supervision, security problems arise in industries.

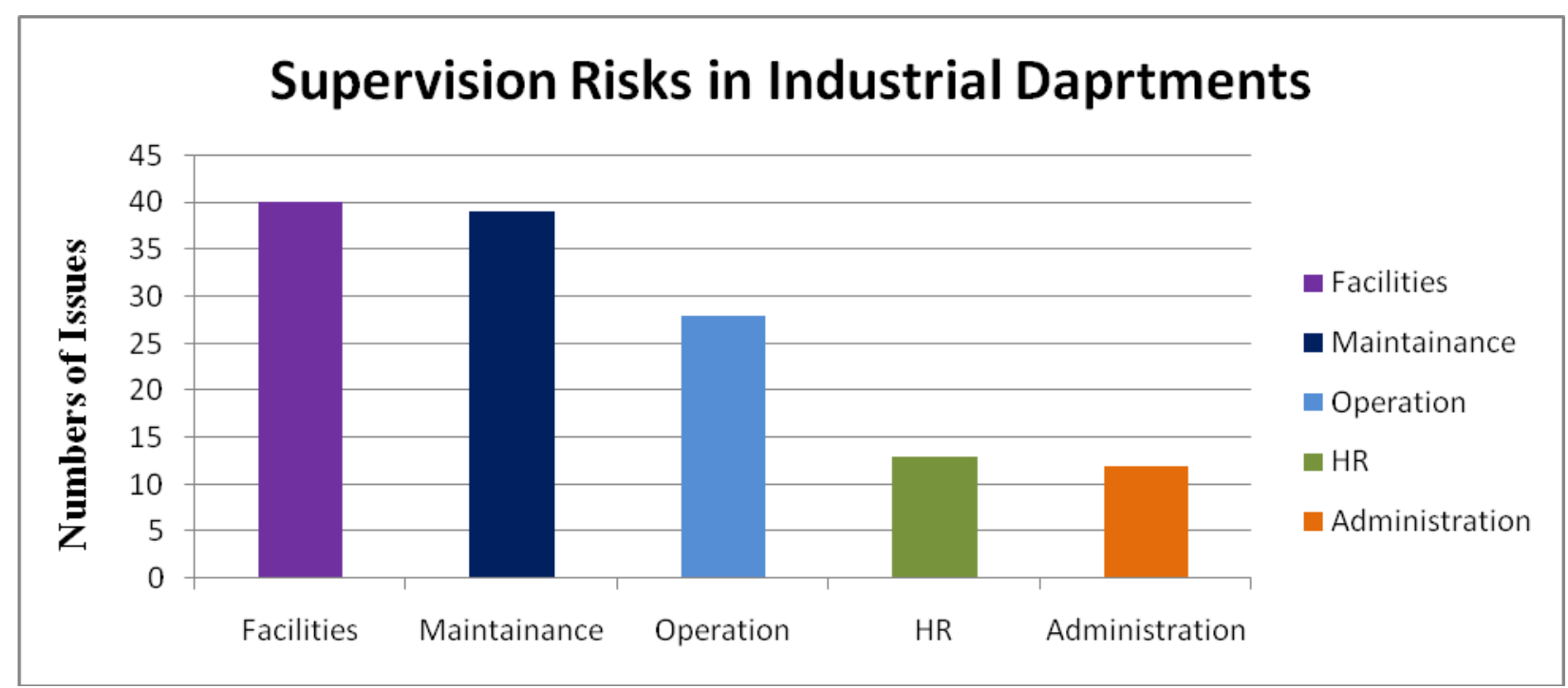

Fig. 2: The safety risks occurred in industrial departments due to lack of supervision in safety management.

Figure 2 shows the safety risks that occurred in industrial departments in an Energy company in 2019 due to a lack of supervision in safety management. The more risks occurred in the facilities department, the lower, the fewer risks in the administration department. In bar graphs on X-axis refer to department name, and $\mathrm{Y}$-axis refers to no. of issues that occurred.

\subsection{Poor Safety Polices}

The industrial policies implement very standard policies for improved performance in different departments. Nevertheless, in safety management, the policies for safety are very poor and negligible. The industries should follow high-level safety management as per the company level.

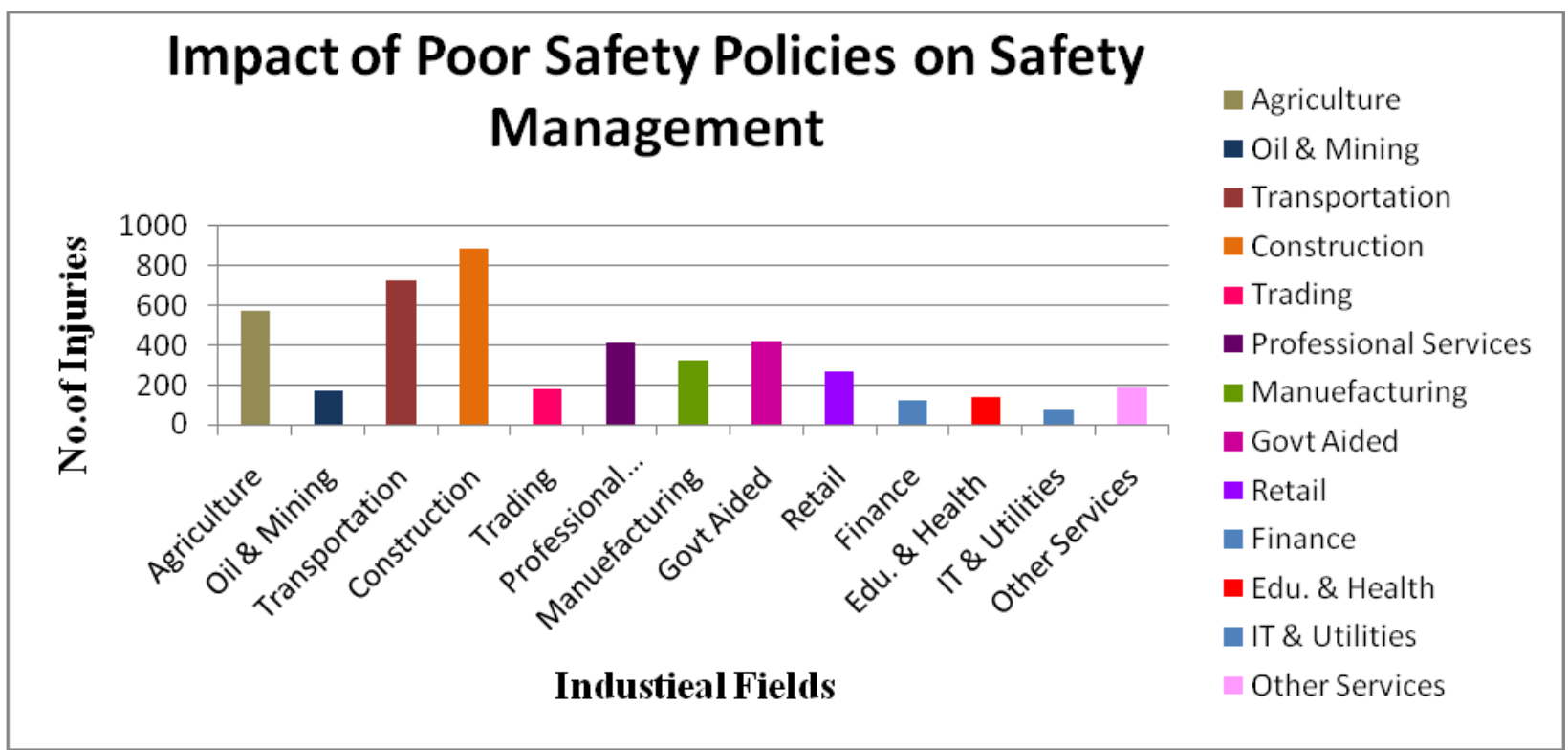

Fig. 3: The Impact of Poor Safety Policies.

Nevertheless, some industries give very little importance to safety management policies. There are no professional managers in the plants in industries that have not set up relevant management departments, increasing safety accidents. Some industries do not implement safety management up to the required level, its influence on the guarantee safety management. Figure 3 shows the injuries that 
occurred with the implementation of low policies in different industrial fields in the year 2019 ((Brocal F. et al. (2019))

\subsection{Equipment Quality}

In industries, the equipment also affects safety management. The weak equipment leads to many safety accidents in industrial plants. The equipment which is a long term used, improper maintenance also influences the safety management. In some cases, the migrant workers also reason for safety risks. They have weak knowledge about the wearing of safety equipment.

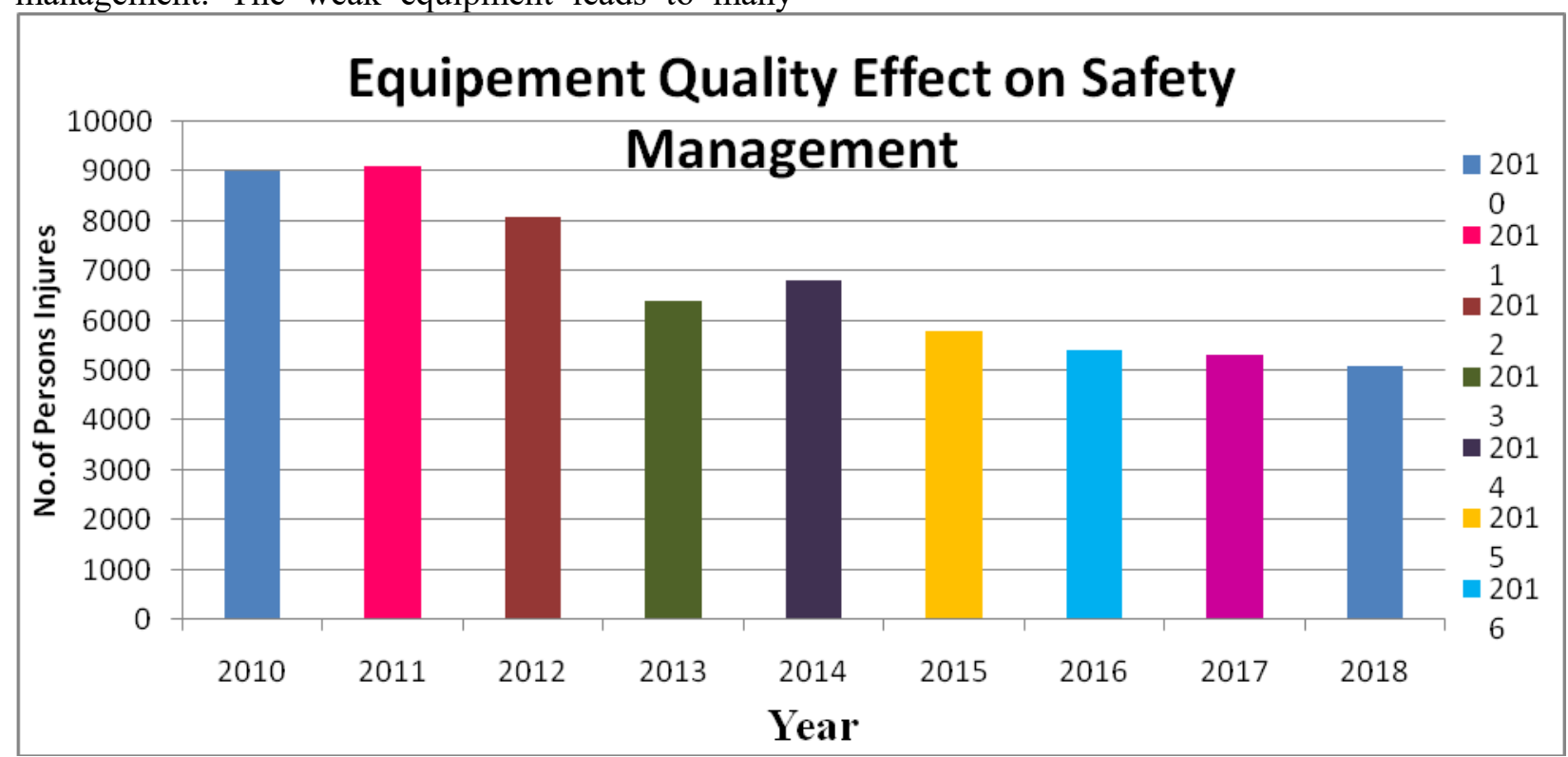

Fig. 4: The number of persons injured each year due to poor quality equipment.

The problem is that firefighting equipment installation also leads to safety management risks. Finally, the poor quality of equipment is the cause of severe safety accidents in industrial plants. Figure 4 describes the number of persons injured each year due to poor-quality equipment in the Energy Sector.

\subsection{Impact of Technology}

In the safety management process, the novel techniques have some hidden hazards. So the industrial management should be aware of the technology that has been newly implemented. The industries can provide investment funds to different departments, but they invest tiny amounts in installing safety technology. It significantly impacts safety management in industrial plants. Finally, the professional knowledge level and ability level are relatively low, and they cannot utilize the technology, increasing the safety risk.

\section{Technology Impact on Safety Management}

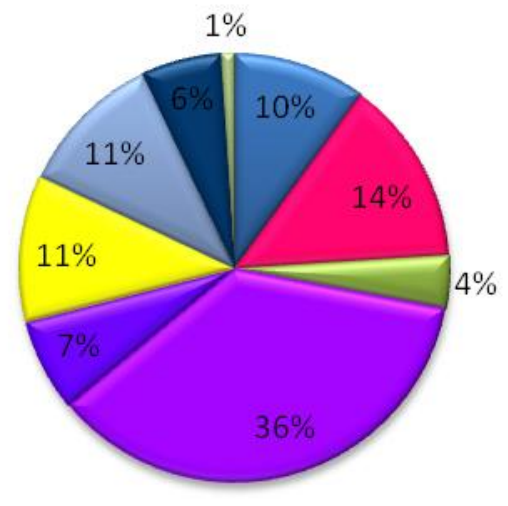

\section{- Maintanance \\ Sanitation \\ $\square$ Oil \& Gas Mining \\ - Construction \\ - Logistics \\ $\square$ Manufacturing \\ $\square$ Coal Mining}

- Healthcare Industry

Fig. 5: Technology impact on safety management. 
Figure 5 can observe the work accidents in different industries due to lack of knowledge on technology and failure to implement novel technologies in safety management. The rate of accidents is high in the construction industry (Brocal F. et al. (2019))

\subsection{Weak Precautions}

In this challenge, discuss the handle of safety accidents that occurs. The safety protection setups and facilities are very poor. The present safety precautions are unable to reach current industry requirements. The safety accident will not be timely through effective measures to reduce the loss caused by the safety accident.

\section{Solutions to Safety Management Challenges and Issues}

\subsection{Industry 4.0}

The best definition for Industry 4.0 paradigm defines the re-imagining of the entire organization and management of the entire value chain in the life cycle of products, which is constantly focused on individual customer needs from the product development and production order to the entire chain, including a product end-user distribution and recycling. In the fourth industrial revolution, devices communicate and synchronize through networks, obtaining only the necessary production information through data mining in the cloud system, enabling intelligent consumers and plants at the application level. With the advent of Industry 4.0, it will also be possible to openly innovate products and processes, instant customer particular product and service development, and customer involvement in these processes. With Industry 4.0, production processes will have the capability to make instant decisions and integrate with other production areas.

According to Muhuri et al. (2019), with the advent of Industry 4.0, the whole transformation through digital integration and intelligent engineering has made a huge leap toward futuristic technology. Today, all gadgets include machine learning capabilities, automation has become a priority, and a new industrial revolution is underway.

Additionally, according to Stock t. et al. (2016), the emergence of industry 4.0 presents enormous prospects for achieving sustainable production.

The fourth industrial revolution is referred to as Industry 4.0 or Smart Manufacturing. In order to realize Smart Manufacturing, several techniques such as cutting-edge ranging from CPS, cloud manufacturing, big data analytics, the Internet of Things, and intelligent sensors to additive production, energy efficiency, and holograms are being developed and implemented on manufacturing sites.

According to Kang et al. (2016), the most critical issues for achieving Smart Manufacturing are technically interoperability, as well as the development of technologies themselves and the requirement for integrated technology, and strategically a system that supports technology development and application according to the purposes, levels, and steps of application for developing and introducing practical technologies.

Emerging information technologies such as the Internet of Things, big data, and cloud computing, in conjunction with artificial intelligence technologies, assist in implementing Industry 4.0's smart factory. S. Wang (2016). Intelligent machines, conveyors, and products interact and negotiate with one another to rearrange themselves for flexible product manufacturing. The industrial network gathers large amounts of data from intelligent things and sends it to the cloud. This offers system-wide feedback and cooperation to maximize system performance via big data analytics. The self-organizing reconfiguration described above and the feedback and coordination enabled by big data provide the structure and operating mechanism of the smart factory.

Alcácer et al. (2019). Industry 4.0 ushers in a new era of digitalization. Everything is digital; business models, settings, production systems, equipment, operators, goods, and services all have a digital component. It's all interwoven within the digital scene's virtual depiction. Physical fluxes will be continuously tracked on digital platforms. At a higher level of automation, numerous systems and software enable factory communications with the latest trends in information and communication technologies, resulting in a state-of-the-art factory, not just inside but also outside the factory, engaging all value chain elements in real-time.

Some sectors have implemented innovations, digitization, and high-tech solutions much earlier. Advanced Digital Production (ADP) technologies used in production have enormous potential to accelerate economic growth and human well-being and protect the environment, contributing to the implementation of the 2030 sustainable development plans (Borowski 2021a).

\subsubsection{Cyber-Physical Systems}

The physical system is a system that people can understand with their five sensory organs. The cyber system should be understood that like cybernetics, a scientific discipline that researches the 
communication and control of living things and machines from the cyber system, the control process is based on information technologies, computers, and the Internet Pfeffer. Cyber-physical systems connect the physical world with the cyber world via the Internet.

Recent advancements in manufacturing have prepared the way for a systematic deployment of Cyber-Physical Systems (CPS), in which information is closely monitored and synced from all relevant viewpoints between the physical factory floor and the cyber computational realm, Lee J. et al. (2015). Additionally, by leveraging modern data analytics, networked machines will be able to operate more effectively, cooperatively, and resiliently. This movement is changing manufacturing into the fourth industrial revolution, dubbed Industry 4.0.

\subsubsection{Horizontal and Vertical Integration}

System Integration allows multiple systems to work together as a single system. In terms of production with Industry 4.0, continuous flow provided by interconnected structures has a critical prescription. To preserve this constant flow and to enable rapid response to changes in production processes and problems, to provide customized products to customers, to increase resource efficiency, to optimize the global supply chain, and to have a more flexible production structure in industry 4.0, horizontal and vertical integration at every point is required. System integration is critical for Industry 4.0 functionality.

Horizontal integration entails a continuous flow of stages between one business's production and planning processes and other enterprises' production and planning processes. This integration encompasses all aspects of the business, from raw material sourcing through Design, manufacturing, marketing, and referral. Horizontal integration between businesses enables the development of new business models as well. Horizontal integration, in a nutshell, generates integrated and end-to-end systems.

\subsubsection{Big Data and Data Analysis}

When we consider Industry 4.0, we see that businesses will begin to gain valuable information due to the massive amounts of data being stored on secure systems and extensively evaluated and transformed into meaningful information about production systems, enterprise systems, and customer-based management systems. When potential failures can be predicted and protections implemented, opportunities may be identified in advance and acted upon immediately. Industry 4.0 solutions allow for communication between man and machine, giving wide opportunities to reduce production costs (Borowski 2021b). Costs associated with manufacturing can be lowered while operations associated with service maintenance are facilitated. Industry 4.0 allows manufacturers to take their production lines to a higher technological level through complete system integration and networking. Industry 4.0 has decentralized analytics, critical decision-making, and increased response time during productions (Borowski 2021b).

To summarize, analysis and forecasting are facilitated across the board, from customer expectations to market movements, hence enhancing decision-making processes and value chains. Additionally, decision-making can occur in real-time.

Di Nardo (2020) emphasizes industry 4.0 concepts, such as control via Cyber-Physical Systems, in a push automation environment where the human operator's function is not marginal, but critical, in addition to supervision and issue solutions. The real-time control of the machines enables the optimal setup of production parameters, ensuring that output remains robust and economic harm caused by equipment failure or maintenance is minimized.

The area of reliability engineering must constantly improve in order to keep pace with industrial and societal changes. This necessitates constant improvement in technological knowledge and capability. In today's technological landscape, with widespread digitization and connectivity at all levels of cyber-physical systems and across all industrial sectors, reliability engineering faces new difficulties and new chances for improvement. Zio (2016) focuses on component and system reliability modeling and discusses some of the issues and possibilities associated with degradation modeling and PHM. These research and application fields have significant potential for enhancing industrial components and systems' safety, productivity, and service capacity. The increasing number of KIDs enable novel modeling and analytic techniques with huge potential benefits. The practical deployment of these new methods must be accompanied by due diligence to ensure that such benefits are collected efficiently.

As Industry 4.0 progresses, and the digital, physical, and human worlds become increasingly integrated, reliability engineering must change to handle current and future concerns. Farsi et al. (2019) outline the concept of Industry 4.0 and address some of the reliability engineering difficulties and possibilities associated with it. The paper proposes new paths for study in system modeling, large data analysis, health management, cyber-physical systems, human-machine interaction, uncertainty, 
collaborative optimization, communication, and interfaces.

The industry 4.0 principles are outlined and the key technologies that enable their creation and diffusion.

\subsubsection{Internet of Things}

Today, the Internet, which we generally know, provides an environment that connects people worldwide and each other, while the Internet of Things connects devices by providing them to communicate with other devices via wired or wireless means. This can be summarized as "Things, (i.e., devices) physically connected to each other and functionally connected to the internet". For example, smart house technologies are based on the Internet of Things solution. Also, a refrigerator can identify the food or vegetables and send messages to the mobile phone through the Internet of Things about storage conditions.

The Internet of Things (IoT) enables seamless connection and interoperability across devices, systems, services, different networks, and in particular, control systems, according to Condry et al. (2016). End consumers anticipate a seamless connection via any endpoint device. Smart Internet of Things devices can act as diverse control system interfaces, enabling quick response and possibly ubiquitous access. Remotely controlled control systems provide dependable, scalable, and long-term solutions for enhanced usability, management, and reaction time.

\subsubsection{Smart Robots}

A robot, which is thinkable first for automation, becomes increasingly autonomous, flexible, and cooperative and costs less. Thus, by analyzing events and situations objectively, robots, which are expected to reduce human-based errors the least, result in increasingly widespread use in the production process. So that, robotics will also be used in factories where Industry 4.0 is used effectively. For example, in smart factories, robots will manage the production process by communicating and recognizing each other, doing work-sharing automatically, analyzing things, and adapting more quickly to changes.

\subsubsection{Virtual Reality}

Virtual reality is described as the "technical reproduction of a real-world process or system through time24." Simultaneously, three-dimensional simulations of goods, materials, and manufacturing processes are used during the design phase, but as we progress toward Industry 4.0, virtual reality will become even more ubiquitous in factory operations. As a result, Virtual Reality is regarded one of Industry 4.0 's primary characteristics. For instance, there is no requirement to wait until the factory is physically completed to determine the efficiency of a fabrication. Industry 4.0 is a virtual environment in which the factory is designed, run, and assessed. Not only the factory as a whole may be reviewed and improved, but also particular manufacturing processes or machines. For instance, workers responsible for repairing and maintaining machinery may receive practical training using virtual reality; even inaccessible components can be viewed, and simulation and virtual reality tools can anticipate failure probability. Additionally, operators will be able to save machine setup time and enhance product quality by identifying possibilities for virtual reality testing prior to actually setting machine parameters for the product on the production line.

\subsubsection{Cloud Computing}

Cloud computing, or online information distribution in its functional sense, is a generic term for services that enable common data sharing among computer devices. When a complete description is produced, the apps, programs, and data are stored on a virtual server (in the cloud) and are easily accessible via the devices while connected to the Internet. In terms of industry 4.0, data mining enables machines to discover the information required for cloud computing manufacturing. The information included in a machine is not limited to a single field; it may potentially span many regions. By facilitating connectivity between smart devices, Big Data, the Internet of Things, and Cloud Computing, we can lay the groundwork for Industry 4.0.

\subsubsection{Smart Factories}

The automation process in Smart factories is happening via an interconnection between machines and devices. For example, if a resource shortage problem happens during the manufacturing process, the resource is ordered automatically without human need, and the malfunctions can be spotted instantaneously only to repair by themselves. Those features help the Smart factory to operate at its maximum capacity without any serious problems.

\subsubsection{Cyber Security}

Security is the very first question when it comes to Data Volume and Intensity. This situation has more importance on systems, aiming to connect unconnected systems before, such as Industry 4.0. Industry 4.0 will increase the number of interconnections and smart devices in factories. 
Cloud connection and the connection between other machines create the intranet of the factory. Besides the intranet, there is an external link to communicate between customers and the factory to smooth out the order and delivery process. Cybersecurity is essential for all those procedures to operate without any problem. However, it is essential to notice that cybersecurity should not interrupt or slow down the manufacturing process while defending the factory to outer-treats. When we point out Cyber Security facts, such as; increasing security and the parts of advanced security developments, we clearly see that a factory that has the advanced features should only be accessible to authorized and educated personnel. This is important for data verification and intensity of data. For instance, critical data should only be viable to authorized personnel in a manufacturing facility. To verify inputs to the system, sources should be secure and verifiable to strengthen their up cyber market; industrial hardware companies buy out or merge with smaller cyber-security companies.

\section{Conclusion}

Process safety management is crucial to industrial production, and safety performance needs to be improved. Many people are concerned about the sustainable growth of many sectors. It has been acknowledged as critical by both industry and academia. These years have seen a renewed emphasis on sustainable development in the engineering curriculum worldwide. Numerous advancements have been achieved in sustainable development, engineering tools, and technology. Nonetheless, industrial events continue to occur.

It is critical to employ engineering concepts to prevent future catastrophes rather than increase sustainable growth. However, the complexity and changing nature of processing plants (which are frequently composed of numerous subsystems that add complexity to the core system) make sustainability a challenge for engineers and an opportunity for them. We may improve process safety performance by embracing novel techniques such as systems analysis of processes and accidents, the use of complex systems methodologies, and multi-scale modeling.

\section{References:}

[1] Industrial safety helmet,industrial safety helmet, industrial safety helmet, industrial safety helmet [tender documents : T459805582]. (2021). MENA Report.
[2] H. Ebrahimi and S. M. Kharghani Moghadam, "An introduction to the industrial town's safety management (ITSM) system," Work (Reading, Mass.), vol. 70, (3), pp. 823-832, 2021.

[3] Nakhal A, A. J., Patriarca, R., Di Gravio, G., Antonioni, G., \& Paltrinieri, N. (2021). Investigating occupational and operational industrial safety data through business intelligence and machine learning. Journal of Loss Prevention in the Process Industries, 73, 104608.

[4] A. A. Artamonov et al, "Mathematical model of chemical process prediction for industrial safety risk assessment," Procedia Computer Science, vol. 190, pp. 107-114, 2021.

[5] G. Vasilescu et al, "Safety assessment of industrial locations under the effects generated by controlled explosions," MATEC Web of Conferences, vol. 342, pp. 1001, 2021.

[6] S. Meramo-Hurtado et al, "Inherent Safety Assessment of Industrial-Scale Production of Chitosan Microbeads Modified with $\mathrm{TiO} 2$ Nanoparticles," Biomolecules

(Basel, Switzerland), vol. 11, (4), pp. 568, 2021.

[7] Li, S.; Zhang, Y.; Feng, R.; Yu, H.; Pan, J.; Bian, J. Environmental Safety Analysis of Red Mud-Based Cemented Backfill on Groundwater. Int. J. Environ. Res. Public Health 2021, 18, 8094.

[8] Li, S.; Zhao, Z.; Yu, H.; Wang, X. The Recent Progress China Has Made in the Backfill Mining Method, Part II: The Composition and Typical Examples of Backfill Systems. Minerals 2021, 11, 1362.

[9] Yu, H.; Li, S.; Wang, X. The Recent Progress China Has Made in the Backfill Mining Method, Part I: The Theory and Equipment of Backfill Pipeline Transportation. Minerals 2021, 11, 1274.

[10] Yu, H.; Zhao, C.; Li, S.; Wang, Z.; Zhang, Y. Pre-Work for the Birth of Driver-Less Scraper (LHD) in the Underground Mine: The Path Tracking Control Based on an LQR Controller and Algorithms Comparison. Sensors 2021, 21, 7839.

[11] Li, S.; Wang, G.; Yu, H.; Wang, X. Engineering Project: The Method to Solve Practical Problems for the Monitoring and Control of Driver-Less Electric Transport Vehicles in the Underground Mines. World Electr. Veh. J. 2021, 12, 64 .

[12] Yu, H.; Li, S. The Function Design for the Communication-Based Train Control (CBTC) System: How to Solve the Problems in the 
Underground Mine Rail Transportation? Appl. Syst. Innov. 2021, 4, 31.

[13] Guo, Q.; Yu, H.; Dan, Z.; Li, S. Mining Method Optimization of Gently Inclined and Soft Broken Complex Ore Body Based on AHP and TOPSIS: Taking Miao-Ling Gold Mine of China as an Example. Sustainability 2021, 13, 12503.

[14] Nardo, M.D.; Yu, H. Intelligent Ventilation Systems in Mining Engineering: Is ZigBee WSN Technology the Best Choice? Appl. Syst. Innov. 2021, 4, 42.

[15] Alcácer, V., et al. (2019). Scanning the Industry 4.0: A Literature Review on Technologies for Manufacturing Systems, Engineering Science and Technology, an International Journal, In Press. https://doi.org/10.1016/j.jestch.2019.01.006

[16] Brocal F. et al. (2019) Emerging Risk Management in Industry 4.0: An Approach to Improve Organizational and Human Performance in the Complex Systems. Hindawi Complexity Volume 2019, Article ID 2089763, 13 pages https://doi.org/10.1155/2019/2089763.

[17] Choi S. et al. (2011) Possibility of Wireless Sensor Networks for Outside Exposed Gas Pipeline Monitoring. International Conference on Information Processing in Sensor Networks Real WIN Workshop, March 2011.

[18] G. H. Choi and B. G. Loh (2017), "Control of Industrial Safety Based on Dynamic Characteristics of a Safety Budget-Industrial Accident Rate Model in the Republic of Korea," Safety and Health at Work, vol. 8, (2), pp. 189197, 2017.

[19] Condry, M.W., et al. (2016). Using smart edge IoT devices for safer, rapid response with industry IoT control operations. Proc. IEEE 104 (5), 938-946.

DOI: $10.1109 /$ JPROC.2015.2513672

[20] J. Le Coze, "Outlines of a sensitising model for industrial safety assessment,"Safety Science, vol. 51, (1), pp. 187-201, 2013.

[21] W. Li, L. Zhang and W. Liang, "An Accident Causation Analysis and Taxonomy (ACAT) model of complex industrial system from both system safety and control theory perspectives," Safety Science, vol. 92, pp. 94103, 2017.

[22] L. M. Steege and B. Pinekenstein, "Addressing Occupational Fatigue in Nurses: A Risk Management Model for Nurse Executives," The Journal of Nursing Administration, vol. 46, (4), pp. 193-200, 2016.
[23] M. Jafari et al, "Development and evaluation of a knowledge risk management model for project- based organizations: A multi- stage study," Management Decision, vol. 49, (3), pp. 309-329, 2011.

[24] D. Kern et al, "Supply risk management: model development and empirical analysis," International Journal of Physical Distribution \& Logistics Management, vol. 42, (1), pp. 60-82, 2012.

[25] M. M. Silverman, "Suicide risk assessment and suicide risk formulation: essential components of the therapeutic risk management model," Journal of Psychiatric Practice, vol. 20, (5), pp. 373-378, 2014.

[26] De Souza et. al (2014) Lopes; Fault Detection and Diagnosis Using Support Vector Machines A SVC and SVR Comparison, Journal of Safety Engineering, Vol.3, No.1, 18-39. DOI: $10.5923 / j . s a f e t y .20140301 .03$

[27] Di Nardo M. (2020). Developing a Conceptual Framework Model of Industry 4.0 for Industrial Management. Industrial Engineering \&

Management Systems Vol 19, No 3, September 2020, pp.551-560.

https://doi.org/10.7232/iems.2020.19.3.551

[28] Farsi M.et al. (2019). Industry 4.0: Some Challenges and Opportunities for Reliability Engineering. IJRRS. 2 (1), p23-34. DOI: 10.30699/IJRRS.2.1.4

[29] Henmi T. et al. (2016). Early Detection of Plant Faults by Using Machine Learning. IEEE. 1 (1), p1-5. DOI: 10.1109/ICAMechS.2016.7813447.

[30] Kang, H.S, et al. (2016). Smart manufacturing: Past research, present findings, and future directions. Int. J. Precis. Eng. Manuf.-Green Technol. 3 (1), 111-128. DOI: 10.1007/s40684-016-0015-5.

[31] Laurentysa C. et al. (2010), Design of a pipeline leakage detection using expert system: A novel approach, Applied Soft Computing, Elsevier, 2010. DOI: $10.1016 /$ j.asoc.2010.02.005

[32] Lee, J. et al. (2015). A cyber-physical systems architecture for industry 4.0-based manufacturing systems. Manuf. Lett. 3, 18-23. DOI: 10.1016/j.mfglet.2014.12.001

[33] Muhuri et al. (2019). Industry 4.0: A bibliometric analysis and detailed overview, Engineering Applications of Artificial Intelligence,78, 218-235. DOI: 10.1016/j.engappai.2018.11.007

[34] Pfeffer A. et al. (2015), "Architectures for integrating functional safety into modular process plants," IFAC-PapersOnLine, vol. 48, 
no. 21, pp. 1321-1326, 2015. DOI: 10.1016/j.ifacol.2015.09.708

[35] Pfeffer A. et al. (2017). HAZOP studies for engineering safe modular process plants. IEEE. 1 (1), p1-4. DOI: 10.1109/ETFA.2017.8247742

[36] Stock, T. et al. (2016). Opportunities of sustainable manufacturing in industry 4.0. Proc. CIRP 40, 536-541. DOI: 10.1016/j.procir.2016.01.129

[37] Wang, S., et al. (2016). Towards smart factory for industry 4.0: a self-organized multi-agent system with big data-based feedback and coordination. Comput. Netw. 101, 158-168. DOI: 10.1016/j.comnet.2015.12.017

[38] Yoon et al. (2008). Automated Monitoring of High-Resistance Connections in the Electrical Distribution System of Industrial Facilities. DOI: $10.1109 / 08 I A S .2008 .172$

[39] Zio E. (2016). Some Challenges and Opportunities in Reliability Engineering. IEEE Transactions on Reliability, Institute of Electrical and Electronics Engineers, 65 (4), 1769-1782. DOI: 10.1109/TR.2016.2591504

[40] Zio E. (2018). The future of risk assessment, Reliability Engineering and System Safety, 177, 176-190.

https://doi.org/10.1016/j.ress.2018.04.020

[41] Borowski P.F. (2021 a). Digitization, digital twins, blockchain, and industry 4.0 as elements of management process in enterprises in the energy sector. Energies, vol. 14, no 7, p. 1885.

[42] Borowski P.F. (2021 b). Innovative processes in managing an enterprise from the energy and food sector in the era of industry 4.0. Processes, vol. 9 , no 2, p. 381.
Contribution of Individual Authors to the Creation of a Scientific Article (Ghostwriting Policy)

Mario Di Nardo, idea, Design, writing Piotr Borowsky, writing, data analysis Maryan Gallab corrections, writing Yu Haouxuan, study and writing preliminary draft Teresa Murino, supervisor

\section{Creative Commons Attribution License 4.0} (Attribution 4.0 International, CC BY 4.0)

This article is published under the terms of the Creative Commons Attribution License 4.0 https://creativecommons.org/licenses/by/4.0/deed.en $\underline{\text { US }}$ 